\title{
Empirical Study on the Relationship between Executive Compensation Dispersion and Firm Performance: the Moderating Role of Technology Intensity
}

\begin{abstract}
This paper examines the moderating effect of technology intensity on the relationship between executive compensation dispersion (ECD) and firm performance in Chinese manufacturing industry. And the multiple linear regression results do confirm that the relationship between the two is sensitive to technology intensity. Specifically, for the publicly listed manufacturing companies with lower technology intensity in China, ECD plays a tournament role and motivates top managers to achieve higher performance. However, for the publicly listed manufacturing companies with higher technology intensity, ECD does not show any significant effect on firm performance. Our finding suggests that technology intensity negatively moderates the relationship between ECD and firm performance which can reconcile the extant disagreements on performance consequences of ECD among scholars to a large degree. We also draw a conclusion that firms with better performance and higher technology intensity tend to have smaller ECD. Meanwhile, the relationship between technology intensity and firm performance is, on average, negative.
\end{abstract}

Keywords: Executive compensation dispersion (ECD); Firm performance; Technology intensity; Listed manufacturing companies

\section{Introduction}

Executive compensation is the key topic of corporate governance in China which is receiving more and more attention from scholars across the world (Kevin C.K. Lam, 2013). Of all the important dimensions of executive compensation, i.e., executive compensation level, executive compensation-performance sensitivity, executive compensation dispersion (ECD) and executive-employees compensation gap, research conclusions on ECD in present literature are the most controversial. ECD, sometimes also termed as executive pay gap or CEO pay gap, mainly refers to the compensation difference between CEO and the other top executives, which also simultaneously reflects the compensation change caused by executives' promotion (K.W. Lee et al., 2008). ECD itself and its effect on firm performance express the distribution pattern and distribution efficiency of total executive compensation, so it can be argued ECD actually reflects both mechanisms of benefits incentive and career advancements (Fang Hu et al., 2013). ECD has key effects on top managers' behavior and attitudes, which would make great significance to improve organizational performance (F. Heyman, 2005). According to the opinion of Henderson and Fredrickson (2001), there are two main competing theoretical views on the topic of performance consequences of ECD, respectively organizational justice theory proposed by Adams (1963) from the behavioral view and tournament theory proposed by Lazear \& Rosen (1981) from the economic view. Tournament theory argues that lager ECD can improve firm performance significantly due to the tournament incentive effect of ECD (K.W. Lee et al., 2008; Leete Laura, 2000, Melton and Zone, 2000, Fang Hu et al., 2013), while organizational behavioral theory argues that larger ECD would lead to executives turnover (Bloom and Michel, 2002) and poor firm performance (P.A. Siegel, D.C. Hambrick, 2005) due to executives' feelings of being exploited or 
sense of unfairness caused by pay inequality within top management teams. Though the two theories both have confirmed that the substantial influence of ECD upon firm performance does exist, it is obvious that, at present, scholars have not reached a consensus on the nature of the influence, i.e., positive performance consequences or negative performance consequences of ECD is still unclear.

Based on the previous literature, it can be found that ECD is a double-edged sword which can improve or harm firm performance. That means the function mechanism of ECD's performance consequences is complicated and it is difficult to grasp accurately. Logically inferring, ECD does have both positive effect argued by tournament theory and negative effect argued by behavioral theory on firm performance simultaneously, and each effect has its prerequisites for reaching a dominant position compared with the other effect. That is to say, different contingent factors will moderate the relative strength of the two opposite effects. Under certain condition, positive effect due to interpersonal competition and material incentive derived by higher ECD will overcome the negative effect, just as the facts that have been confirmed by the tournament theory literature; On the other hand, under other conditions, negative effect due to counterproductive behavior and dissatisfaction derived by higher ECD will exceed the positive effect, just as the results that have been proved by the behavioral theory literature. Consequently, for scholars, it is critical to find out such contingent factors and further investigate its moderating effect on the relationship between ECD and firm performance. This study takes technology intensity as the critical contingent variable and tries to discuss the moderating effect of technology intensity on the relationship between ECD and firm performance.

\section{Literature review and hypothesis}

\subsection{Performance consequences of ECD in economic view}

Traditional economic theory argues that agent's compensation should be determined according to his marginal output by the principal in order to make agent reach his optimal effort level. If it can be realized in practice, the principal can make the compensation decisions according to the agent's marginal contribution, and thus such decision-making behavior is rather easy. However, the effectiveness of such behavior needs a prerequisite described as that the supervision of executive is accurate with a lower cost, which can not be satisfied at all. Therefore, shareholders and the boards, as the principal, begin turning to the incentive of tournament.

Tournament theory demonstrates that when the monitoring cost on the agents is rather high, the principal would try to motivate the agents adopting their relative performance instead of the absolute performance. Since the winner in the tournament will get most of the prizes, while the losers will even get nothing, the high ECD will provide the competitors great motivation to try to win. In TMT, top executives should try to do better than others to get promotion. Eventually, the competition results will improve firm performance. Therefore, in order to induce higher effort level from the executives, a relative higher ECD is necessary. All in all, the tournament theory regards that with the increase of the monitoring cost under the conditions of more popular teamwork, higher ECD can lower the monitoring cost and thus provide strong incentives for the alignment of shareholders' and executives' interests. That is to say, higher ECD can lead to higher firm performance.

Since the appearance of tournament theory by Lazear and Rosen (1981), many scholars have 
empirically tested the positive performance consequences of ECD (Jing Chen et al., 2011). For example, Eriksson (1999) takes Denmark firms as the sample, adopting coefficient of variation and CEO-employees pay gap as the measurement of ECD, and confirms that ECD is positively with firm performance. Brian G M Main et al. (1993) take 200 American firms as the sample, adopting the sum of cash compensation and prizes as the base of calculating ECD, and finally proves that ECD is positively both with the financial performance and market performance. By adopting the method of ordinary least squares (OLS) regression analysis, Bing-Xuan Lin and Rui Lu(2009) have shown that, for the publicly traded companies in China, compensation gap between senior executives, another term of ECD, plays a tournament role and motivates managers to achieve higher level of performance.

\subsection{Performance consequences of ECD in behavioral view}

Behavioral view focuses on the influence of ECD on team cooperation. Different with the tournament theory which supports large ECD, from the perspective of psychology, behavioral theory regards that ECD is one of the important components of social psychological and social political environment, which have effects on individual's intentions choice between pursuing his own benefits and cooperating with others for shared goals.

According to social comparison theory, a branch of behavioral view, executives intend to seek for distribution justice at the preconditions of both overestimating their own output and capability and weakening the input of their peers, especially CEO (O'Reilly III Charles A. et al., 1988; J. W. Fredrickson et al., 2010). Therefore, even CEO or some executives really do more contributions than others, an objectively fair ECD would still lead to the sense of unfairness. Once the dissatisfaction emerges, the work effort will decrease, and the counterproductive effort will occur, eventually the firm performance would be damaged. According to relative deprivation theory, another branch of behavioral theory, if executives find that their compensation is lower than expected, they will feel a sense of been exploited, which will naturally lead to negative workplace behavior, such as free riding, sabotage, strike, and negative attitudes, including carelessness on organizational objectives and the decrease of cohesion and commitment to the firms (Paul D. Sweeney, 1990). That is to say, ECD is the base of comparison among executives, and if they feel being exploited, they will not cooperate and do some negative behavior which is harmful to teamwork. Consequently, firm performance will be affected negatively. According to organizational political theory, the third branch of behavioral view, since the too fierce competition among executives will be full of political behaviors, which will weaken the cooperation conversely, so too large ECD is not good to firm performance. ECD motivates executives to win, while there are many ways to win. Of which, to involve into political behavior is the most common way, since such behavior, for example, bribery, rent seeking, and destroying, is very free in cost, easy in difficulty, and most of important, difficult to observe (Erin Landells, \&Simon L. Albrecht, 2013). Therefore, too large ECD will lower firm performance by destroying the cooperation intentions among executives.

Several empirical studies have confirmed such a negative effect of ECD on firm performance based on the behavioral theory (P.A. Siegel, \&D.C. Hambrick, 2005). For example, using a sample of 781 U.K. firms over the period 2000-2008, Anna Zalewska (2014) studies the relationship between ECD and firm performance and confirms that British companies are characterized by a negative dispersion-performance relationship, i.e., the greater the dispersion is, the worse the firm 
performance is. And when studying the relationship between CEO-TMT (top management team)

total pay gap and firm performance, Mason A. and Gerard Sanders (2004) find that the pay gap has negative effects on firm performance.

\subsection{Performance consequences of ECD hypothesis considering the moderating role of technology intensity}

The past literature has investigated the performance consequences of ECD very deeply, for example, both empirically and theoretically in method, both foreign and domestic in region, both long time ago and recently in time horizon. Most of the studies do confirm the existence of the effect of ECD on firm performance, however the specialized functioning mechanisms, i.e., effect strength and effect nature, have not been reached a consensus. Besides, there is still some particular literature arguing that variation in executive team pay plays little role in determining company performance (Martin J. Conyon et al., 2001). The reason of such complex debates on this issue is that past literature has rarely considered the functioning context of ECD, which actually determines the final performance consequences of ECD. Logically reasoning based on theoretical analysis and practical observation, technology intensity may be one of such a critical contingent context variables. The most important and obvious reason is that technology-intensive firm is technology and innovation intensive, and these activities need a higher level of team collaboration among top executives, while labor-intensive firm does not need that. So a higher ECD might lead to hostile competition which could potentially reduce collaboration and harm firm performance(Ying-Fen Lin, et al., 2013). Therefore, ECD will have different effects on firm performance under different technology intensities. Besides, there are still two implicit reasons that can explain the moderating role of technology intensity in the relationship between ECD and firm performance.

First, larger ECD would induce managerial myopia in behavior, which is significantly negative related with firm performance in technology-intensive firms. Since higher ECD is based on executives' short-term performance, they will put more energy in resolving the emergent day-to-day problems, while ignoring the input in long-term strategic planning and knowledge-based capability accumulation. Such managerial myopia will do great harm to technology-intensive firms as long-term perspective is very critical to such firms. On the contrary, labor-intensive firms may not be so sensitive to managerial myopia as technology-intensive firm, since such firms are facing with a relative more stable environment which decreases the value of long-term perspective.

Second, larger ECD will lead to higher turnover rate, or at least turnover intention, of executives in technology-intensive firms. Executives in technology-intensive firms generally are more likely "top stars" in their professional fields, and thus they have not only better knowledge stock and professional expert, but also stronger sense of pride than their peers. Therefore, if ECD is too large, executives in certain fields will necessarily get much lower compensation than expected, especially compared with the executives in other fields. That is a great challenge to the executives who get lower compensation, and they usually regard it as an insult to themselves and their profession. And according to some researches, pay inequality is an important determinant of managerial turnover, and top managers are more likely to resign when paid less than firm peers. What's more, turnover intention increases with greater levels of pay inequality(Jayant R. Kale, et al., 2014) Since they are facing too many potential job opportunities, executives in technology-intensive firms will show higher turnover intention or lower commitment to the firms. Consequently, firm performance will 
be affected negatively.

According to the discussion above, we propose the following hypothesis.

H1: Technology intensity can negatively moderate the relationship between ECD and firm performance.

\section{Method}

\subsection{Sample}

Taking Chinese manufacturing listed enterprises in Shenzhen and Shanghai Stock Exchange during 2008-2012 as the subjects to be investigated, the paper designs and chooses the research sample in accordance with the following criteria. First, in order to get a balanced panel sample with a five-year period, the firms should have gone public at least since 2007. Second, the firms ever marked by ST, PT, SST and *ST during the five years should be eliminated from the sample, since the financial data of such firms usually may be abnormal which can lead to systematical bias of empirical results. Third, firms that have not published all the complete data in their annual reports of each year over 2008-2012 which are required in this study should be removed from the sample. Fourth, firms with outlier in executive compensation should be removed, since the exact executive compensation data are critical to the effectiveness of this study. For example, if a firm CEO's compensation is lower than the average level, then this firm should be removed from the sample, because such data is an outlier. The last but not the least, in order to assure the normal distribution of firm performance, the firms with extreme performance should be removed from the sample, since the normality of firm performance, as the sole dependent variable in this study, is critical to the reliability and validity in research. In this study, we respectively remove $1 \%$ firms with the top highest performance and $1 \%$ firms with the lowest performance in the quasi sample.

According to the above five conditions, 782 listed firms are chosen as the final whole sample. Since each firm has the data of five years, we finally get a sample of 3910 firm-years. Of the 782 listed firms, 230 firms are titled as technology-intensive enterprises belonging to sub-sample TI_SS, consisting of 1150 firm-years, which include Computer Communications and other Electronic Equipment Manufacturing Industry, Automobile Manufacturing Industry, Pharmaceutical Manufacturing Industry, Special Equipment and Shipbuilding Manufacturing Industry, Aerospace Manufacturing industry. The other 552 firms are treated as labor-intensive enterprises belonging to sub-sample LI_SS, consisting of 2760 firm-years, since they belong to the relatively more traditional sub-industries of manufacturing industry. It is worth to point out that some firms in traditional sub-industries that have been approved as high-tech enterprises by the government, no matter local or central, are treated as technology-intensive enterprises. Most data are selected from the Financial Research Database of CSMAR and RESSET, and part of the data are selected from the annual reports of listed firms which can supplement the missing data and inaccurate data of the commercial research database. In order to assure data accuracy, the data of $1 \%$ sample firms in LI_SS and TI_SS sourced from the database are randomly selected to compare with the corresponding data sourced from the annual reports by hand. The comparison results do confirm the validity of the final sample data.

\subsection{Measurement}

There are four groups of research variables in this study, respectively, explanatory variable, dependent variable, moderating variable and control variable. 
Measure of explanatory variable: ECD is the sole explanatory variable in this study. And it is operationally defined as the difference between the highest compensation and the average compensation of the TMT. We argue that the highest compensation must belong to CEO and the average compensation is defined as the ratio of the total compensation of the whole TMT to the number of the top managers who get compensation from the listed firms.

Measure of dependent variable: Firm performance is the sole dependent variable in this study, which is operationally defined as Earnings Per Share (EPS) and Return on Assets (ROA) of the next year. To be specific, EPS is calculated as the ratio of net profits to share numbers, and ROA is calculated as the ratio of net profits to total assets. EPS will be the main measure index of firm performance which will be used to test the hypothesis, while ROA will be the supplementary measure index of firm performance which will be applied in the robustness test.

Measure of moderating variable: Technology intensity, coded as TI, is treated as the sole moderating variable that can affect the relationship between ECD and firm performance in this study. TI is operationally defined as a dummy variable, which equals to 1 when the sample firms belong to TI_SS, while equals to 0 when the sample firms belong to LI_SS.

Measure of control variables: According to extant literature, firm size (V. Chaiporn, \&T. Jittima, 2015), debt to assets ratio (N. S. Sadeghian et al., 2012), ownership concentration (John S. Earle et al., 2005), managerial ownership (Pinar Mandaci, \&Guluzar Gumus), independent director ratio (Hsiang-Lan Chens, 2014), supervisory board governance characteristics (B. Mahmudi, E. Nurhayati, 2014), and top management team size (J. Haleblian, S. Finkelstein, 1993) can significantly influence firm performance to different degree by different ways. Therefore, we choose the above constructs as the control variables in this study. Firm size, coded as FS, is measured by the natural logarithm of revenue. Debt to assets ratio, coded as DAR, is defined as the ratio of debt to the total assets. Ownership concentration, coded as $\mathrm{OC}$, is defined as the share holding rate of the first large shareholder. Managerial ownership, coded as MO, is defined as the natural logarithm of executives holding number. Independent director ratio, coded as IDR, is defined as the ratio of the number of independent directors to the size of board of directors. Governance characteristic of supervisory board, coded as SBGC, is measured by the number of supervisors in this study. Top management team size, coded as TMTS, is defined as the number of top managers who get compensation from the listed firm.

\subsection{Data}

\subsubsection{Descriptive statistics results of research variables}

By applying SPSS17.0, the descriptive statistics analysis of the research variables is executed, and the results are shown in Tab.1. In order to assure the normality of the research variables in distribution in case the risk of spurious regression in our analysis, the paper also has implemented both the analysis on Skewness and Kurtosis and the Histogram of the main research variables. The results show that the data in our sample are suitable for linear regression analysis.

Table.1 Descriptive statistics of research variables

\begin{tabular}{|c|c|c|c|c|c|c|}
\hline & $\mathrm{N}$ & Minimum & Maximum & Mean & Std. Deviation & Variance \\
\hline ECD & 3910 & 1027 & 5068200 & 206772.50 & 274147.374 & $7.516 \mathrm{E} 10$ \\
\hline ROA & 3910 & -.3802 & .8538 & .049076 & .0757908 & .006 \\
\hline
\end{tabular}




\begin{tabular}{|lllllll|}
\hline EPS & 3910 & -2.39 & 12.82 & .2924 & .54696 & .299 \\
TI & 3910 & 0 & 1 & .29 & .456 & .208 \\
FS & 3910 & 14.54 & 26.13 & 21.3086 & 1.36445 & 1.862 \\
DAR & 3910 & .00707988 & .99696429 & .4807140818 & .19048 & .03621 \\
OC & 3910 & 3.62 & 85.23 & 34.9614 & 14.59508 & 213.016 \\
MO & 3910 & .00 & 20.74 & 8.5678 & 6.72222 & 45.188 \\
SBGC & 3910 & 1 & 16 & 4.99 & 2.382 & 5.676 \\
IDR & 3910 & 7.140 & 66.670 & 35.17075 & 9.068057 & 82.230 \\
TMTS & 3910 & 4 & 37 & 14.59 & 4.198 & 17.624 \\
\hline
\end{tabular}

According to Tab.1, the mean of ECD is 206772.50, which means on average CEO will get an excess compensation of more than 200 thousands RMB Yuan compared to the other top managers. Obviously, ECD of Chinese manufacturing industry has grown to a very high level, which is $40 \%$ higher than the level of year 2000. The mean of ROA is $4.9076 \%$, which means firms of Chinese manufacturing industry are running at a rather low profit rate, and especially it is true when we compare this ROA level with GDP growth rate of China over the same period. In general, the development of manufacturing industry in China lags far behind the development of whole economy. Such a poor profitability of manufacturing industry demonstrates that China is just a "large manufacturer" instead of a "powerful manufacturer".

\subsubsection{Correlation analysis}

By adopting the method of Pearson correlation analysis with SPSS17.0, the correlations among all the above research variables with 2-tailed significance are shown in Tab.2. In Tab.2, most of the variables are significantly correlated with each other, and especially it is true that there are significant relationships among EPS, the sole dependent variable, ECD, the sole explanatory variable, and TI, the moderating variable. What is more, the relationship in nature is confirming to the research hypothesis. Most of the correlations between control variables and dependent variable are significant and all the correlations are below than 0.5 , which means that the choice of control variables is appropriate, and there is an acceptable risk in multicollinearity, therefore the variables are suitable for regression analysis.

Table 2. Pearson Correlations Among Research Variables

\begin{tabular}{|c|c|c|c|c|c|c|c|c|c|c|}
\hline & EPS & ECD & FS & DAR & $\mathrm{MO}$ & $\mathrm{OC}$ & SBGC & IDR & TMTS & TI \\
\hline EPS & 1 & & & & & & & & & \\
\hline ECD & $.262^{* *}$ & 1 & & & & & & & & \\
\hline FS & $.303^{* *}$ & $.331^{* *}$ & 1 & & & & & & & \\
\hline DAR & $-.153^{* *}$ & -.005 & $.346^{* *}$ & 1 & & & & & & \\
\hline MO & $.041^{*}$ & $.122^{* *}$ & .013 & $-.117^{* *}$ & 1 & & & & & \\
\hline OC & $.104^{* *}$ & $-.035^{*}$ & $.275^{* *}$ & $.047^{* *}$ & $-.226^{* *}$ & 1 & & & & \\
\hline SBGC & -.003 & .020 & $.146^{* *}$ & $.152^{* *}$ & $-.137^{* *}$ & .005 & 1 & & & \\
\hline IDR & -.024 & .007 & -.020 & $-.062^{* *}$ & $.077^{* *}$ & $.043^{* *}$ & $-.136^{* *}$ & 1 & & \\
\hline TMTS & $.095^{* *}$ & $.261^{* *}$ & $.245^{* *}$ & $.112^{* *}$ & $.142^{* *}$ & $-.094^{* *}$ & $.199^{* *}$ & $.064^{* *}$ & 1 & \\
\hline
\end{tabular}




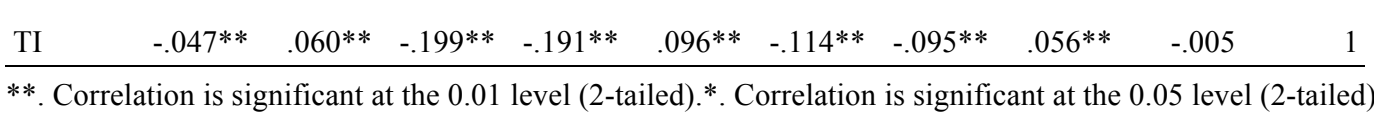

$$
\begin{aligned}
& \text { Valid N: } 3910 .
\end{aligned}
$$

\subsection{Model}

The most commonly used method in testing moderating effect is mutivariate regression analysis with the interaction item consisting of the moderating variable and explanatory variable. In this study, we construct a regression model shown in Model 1. In Model 1, ZECD represents the standardized value of ECD, ZTI represents the standardized value of TI, and both of them are handled by SPSS19.0. If $\beta_{10}$ is significantly negative, and we can draw a conclusion that TI actually can negatively moderate the relationship between ECD and firm performance. H1 can be tested to a large degree.

$$
\begin{gathered}
E P S_{i}=\alpha+\beta_{1} F S_{i}+\beta_{2} D A R_{i}+\beta_{3} M O_{i}+\beta_{4} O C_{i}+\beta_{5} S B G C_{i}+\beta_{6} I D R_{i}+ \\
\beta_{7} T M T S_{i}+\beta_{8} T I_{i}+\beta_{9} E C D_{i}+\beta_{10} Z E C D_{i} * Z T I_{i}+\varepsilon_{i}
\end{gathered}
$$

However, the multicollinearity problem of the above method is rather tremendous due to the existence of the interaction item, which can actually weaken the validity of the statistical results of Model 1. Therefore, in order to further strengthen the reliability of the empirical results, we propose another supplementary method called sub-sample comparison analysis. We split the whole sample into two sub-samples, respectively TI_SS and LI_SS, according to the technology intensity level of each firm. TI_SS consists of firms with higher technology intensity, and LI_SS consists of firms with lower technology intensity. We construct Model 2 to compare $\beta_{9}$ between TI_SS and LI_SS,

which is the regression coefficient of ECD. If $\beta_{9}^{\prime}$ in TI_SS is significantly smaller than that in LI_SS, then it can be concluded H1 holds.

$$
\begin{gathered}
E P S_{i}=\alpha+\beta_{1}^{\prime} F S_{i}+\beta_{2}^{\prime} D A R_{i}+\beta_{3}^{\prime} M O_{i}+\beta_{4}^{\prime} O C_{i}+\beta_{5}^{\prime} S B G C_{i}+\beta_{6}^{\prime} I D R_{i}+ \\
\beta_{7}^{\prime} T M T S_{i}+\beta_{8}^{\prime} T I_{i}+\beta_{9}^{\prime} E C D_{i}+\varepsilon_{i}
\end{gathered}
$$

If the results of the two methods both confirm $\mathrm{H} 1$, then the test of $\mathrm{H} 1$ has high validity and reliability. Otherwise, the rationality of $\mathrm{H} 1$ still needs further investigation with cautiousness.

\section{Results and Discussion}

\subsection{Moderating effect test by interaction analysis}

By adopting the whole sample, we use Model 1 which contains the interaction item "ZECD*ZTI" to test the moderating effect of technology intensity on the relationship between ECD and firm performance. The results are shown in Tab.3.

According to Tab.3, ECD is positively related to firm performance (Beta=0.234, T=11.804), which means, on the whole, the positive effect of ECD still exceeds the negative effect of ECD at present in Chinese manufacturing firms. The standardized coefficients of TI is $-0.035(\mathrm{P}=0.020)$, which means firms with higher technology intensity have a relatively lower performance than firms 
with lower technology intensity in China. It is noteworthy that the standardized coefficients of the interaction item $(\mathrm{ZECD} * \mathrm{ZTI})$ is $-0.129(\mathrm{P}=0.000)$, which means each percent positive change of technology intensity will lower 0.129 percent of the positive effect of ECD on firm performance. In another word, technology intensity can negatively moderate the relationship between ECD and firm performance. H1 holds.

Table 3. Regression results of Model 1 with the whole sample

\begin{tabular}{|c|c|c|c|c|c|}
\hline \multirow[b]{2}{*}{ Model } & \multicolumn{2}{|c|}{$\begin{array}{c}\text { Unstandardized } \\
\text { Coefficients }\end{array}$} & \multirow{2}{*}{$\begin{array}{c}\text { Standardized } \\
\text { Coefficients } \\
\text { Beta }\end{array}$} & \multirow[b]{2}{*}{$\mathrm{t}$} & \multirow[b]{2}{*}{ Sig. } \\
\hline & $\mathrm{B}$ & Std. Error & & & \\
\hline (Constant) & -2.131 & .141 & & -15.153 & .000 \\
\hline FS & .130 & .007 & .323 & 18.135 & .000 \\
\hline DAR & -.008 & .000 & -.270 & -17.098 & .000 \\
\hline $\mathrm{OC}$ & .001 & .001 & .034 & 2.172 & .030 \\
\hline MO & .000 & .001 & -.007 & -.467 & .641 \\
\hline SBGC & -.006 & .003 & -.027 & -1.787 & .074 \\
\hline IDR & -.002 & .001 & -.038 & -2.586 & .010 \\
\hline TMTS & .002 & .002 & .013 & .817 & .414 \\
\hline $\mathrm{ECD}$ & $4.674 \mathrm{E}-7$ & .000 & .234 & 11.804 & .000 \\
\hline TI & -.042 & .018 & -.035 & -2.324 & .020 \\
\hline ZECD*ZTI & -.114 & .016 & -.129 & -7.028 & .000 \\
\hline Model Summary & $\mathrm{R}$ & $.447^{\mathrm{a}}$ & R Square & & .198 \\
\hline ANOVA & $\mathrm{F}$ & 97.288 & Sig. & & $.000^{\mathrm{a}}$ \\
\hline
\end{tabular}

\subsection{Moderating effect test by sub-sample comparison}

In order to recognize the different effects of ECD on firm performance under different technology intensities and further confirm the validity of $\mathrm{H} 1$, we use Model 2 to make regression analysis by respectively adopting TI_SS and LI_SS. The results are shown in Tab.4 and Tab.5.

Table 4. Regression results of Model 2 with TI_SS

\begin{tabular}{|c|c|c|c|c|c|}
\hline & \multicolumn{2}{|c|}{$\begin{array}{c}\text { Unstandardized } \\
\text { Coefficients }\end{array}$} & \multirow{2}{*}{$\begin{array}{c}\text { Standardized } \\
\text { Coefficients } \\
\text { Beta }\end{array}$} & \multirow[b]{2}{*}{$\mathrm{t}$} & \multirow[b]{2}{*}{ Sig. } \\
\hline & B & Std. Error & & & \\
\hline (Constant) & -2.006 & .211 & & -9.504 & .000 \\
\hline FS & .120 & .011 & .357 & 11.272 & .000 \\
\hline DAR & -.008 & .001 & -.341 & -12.073 & .000 \\
\hline OC & .002 & .001 & .049 & 1.778 & .076 \\
\hline MO & $5.114 \mathrm{E}-5$ & .002 & .001 & .029 & .977 \\
\hline SBGC & -.010 & .005 & -.051 & -1.881 & .060 \\
\hline IDR & .000 & .001 & -.009 & -.344 & .731 \\
\hline
\end{tabular}




\begin{tabular}{lrrrrr}
\hline TMTS & .005 & .003 & .050 & 1.729 & .084 \\
ECD & $\mathbf{3 . 5 9 1 E - 8}$ & .000 & .028 & .951 & .342 \\
\hline Model Summary & $\mathrm{R}$ & .443 & R Square & .196 & \\
ANOVA & $\mathrm{F}$ & 34.756 & Sig. & $.000^{\mathrm{a}}$ & \\
\hline
\end{tabular}

${ }^{a}$ Dependent Variable: EPS; $\mathrm{N}=1150$.

In Tab.4, there is no significant relationship between ECD and firm performance (Beta $=0.028$, $\mathrm{P}=0.342$ ). That means, in technology-intensive firms, the net effect of ECD on firm performance is nearly zero. It can be further concluded that firms with higher technology intensity in Chinese manufacturing industry have reached the balanced ECD level, which indicates that if ECD was enlarged a little more, then the net effect of ECD on firm performance would be negative, while if ECD was reduced a little more, then the net effect would be positive.

Table 5. Regression results of Model 2 with LI_SS

\begin{tabular}{|c|c|c|c|c|c|}
\hline & \multicolumn{2}{|c|}{$\begin{array}{c}\text { Unstandardized } \\
\text { Coefficients }\end{array}$} & \multirow{2}{*}{$\begin{array}{c}\text { Standardized } \\
\text { Coefficients } \\
\text { Beta }\end{array}$} & \multirow[b]{2}{*}{$\mathrm{t}$} & \multirow[b]{2}{*}{ Sig. } \\
\hline & B & Std. Error & & & \\
\hline (Constant) & -2.137 & .177 & & -12.092 & .000 \\
\hline FS & .132 & .009 & .306 & 14.486 & .000 \\
\hline DAR & -.008 & .001 & -.244 & -13.133 & .000 \\
\hline OC & .001 & .001 & .030 & 1.586 & .113 \\
\hline MO & -.001 & .002 & -.013 & -.702 & .483 \\
\hline SBGC & -.006 & .004 & -.023 & -1.284 & .199 \\
\hline IDR & -.003 & .001 & -.048 & -2.740 & .006 \\
\hline TMTS & .000 & .003 & .001 & .067 & .946 \\
\hline ECD & $5.163 \mathrm{E}-7$ & .000 & .216 & 11.305 & .000 \\
\hline Model Summary & $\mathrm{R}$ & .452 & R Square & .204 & \\
\hline ANOVA & $\mathrm{F}$ & 88.191 & Sig. & $.000^{\mathrm{a}}$ & \\
\hline
\end{tabular}

${ }^{a}$ Dependent Variable: EPS; $\mathrm{N}=2760$.

In Tab.5, there is a significant positive relationship between ECD and firm performance (Beta $=0.216, \mathrm{P}=0.000$ ). It can be learned that in firms with lower technology intensity in Chinese manufacturing industry, ECD has net positive effect on firm performance. In general, most of the firms with lower technology intensity can improve their performance by increasing their present ECD.

The comparison between Tab. 4 and Tab.5 shows that there is a significant difference between the effects of ECD on firm performance under different technology intensities. Specifically, under the condition of high technology intensity, ECD has no effect on firm performance, while under the condition of lower technology intensity, ECD plays a tournament role and shows a very significant positive effect on firm performance. Therefore, we argue that technology intensity can negatively moderate the relationship between ECD and firm performance. H1 still holds. 


\subsection{Robustness test}

We try three methods to do robustness test. First we test whether the empirical results still hold when the measure of firm performance changes. In Model 1 and Model 2, EPS, the dependent variable, is replaced by ROA as the new alternative measure of firm performance, respectively called Model 1' and Model 2'. By adopting Model 1', regression analysis with interaction item is carried on with the whole sample, and further by adopting Model 2', regression analysis is carried on respectively with TI_SS and LI_SS. The regression results show that, even taking ROA as the measure of firm performance, $\mathrm{H} 1$ still holds.

Second, we test whether the empirical results are robust with the change of the measure of ECD. ECD, originally measured by the difference between CEO compensation and the average compensation of the TMT, is redefined as the ratio of CEO compensation to the average compensation of the TMT. In Model 1 and Model 2, a new measure of ECD is adopted. Both the interaction analysis with the whole sample and the sub-sample comparison analysis with TI_SS and LI_SS confirm our hypothesis. In fact, the moderating effect of technology intensity on the relationship between ECD and firm performance gets even more significant when we change the measure of ECD. That is to say, test results are robust with the change of the measure of ECD.

Third, we test whether the empirical results are robust with the change of control variables. FS, DAR, OC, MO, SBGC, IDR and TMTS are gradually removed from Model 1 and Model 2 step by step, and finally there is no control variable in the regression models. During the process, all the regression results confirm the hypothesis. Besides, we choose CEO duality, technology intensity, supervisory number and ratio of female executives as the new control variables, and put them into Model 1 and Model 2. The regression results prove the hypothesis, too. Therefore, the validity of $\mathrm{H} 1$ is not dependent on the choice of control variables.

\subsection{Discussion}

Data analysis has proved the research hypothesis in this paper soundly, and robustness test has confirmed the reliability and validity of the empirical results. It can be concluded exactly that technology intensity would negatively moderate the relationship between ECD and firm performance.

On closer scrutiny, besides the two implicit reasons mentioned in part 2, the moderating role of technology intensity may be fulfilled through another way. Larger ECD in Firms will lower risk taking intentions and failure tolerance of top managers, which would naturally damage performance of technology-intensive firms. Under the condition of higher technology intensity, non-routine innovative business issues take a greater proportion in the whole business issues, which need more innovative methods. However, trying initiatives in resolving such issues would be of higher failure possibility. If ECD is too large, top managers will not try new methods of doing their jobs or resolving the business issues, since new methods are of higher risk to lose. And what is more, according to the latest research, people in firms need private spaces so badly, which is not only for the concentration, but also the essential for stressful working environment(Christine Congdon, et al., 2014).So the top managers would not like to cooperate with each other. Instead, they intend to compete too fiercely among each other under lager ECD. For top managers, it may be reasonable to maintain their own compensation level by avoiding temporary failure. However, for firms with higher technology intensity, such behavior are fatal to firm performance since most of the innovative business issues in such firms face the absence of effectiveness improvement due to top 
managers' risk aversion.

Such a conclusion can reconcile the extant debates on the effect of ECD on firm performance. And the conclusion on the moderating role of technology intensity has several implications both in theory and practice. First, technology intensity affects firm performance mainly by the indirect moderating role instead of direct fixed effect. Second, for firms with higher technology-intensity, the negative effect of ECD on firm performance grows faster than the positive effect of ECD. At present, ECD in firms with higher technology-intensity has reached its balanced level, which means ECD in these firms should not be enlarged any more. Otherwise, the net effect of ECD will be negative. Since CEO with higher power generally has the intention to enlarge ECD at their own will (Shuo Wang, Changzheng Zhang, 2015), so the boards in firms with higher technology-intensity should pay more attention to prevent such a behavior. Third, for firms with lower technology-intensity, the net effect of ECD on firm performance is significantly positive. There has some potential room for such firms to enlarge ECD in order to get higher firm performance. Fourth, larger ECD would damage top managers' long-term perspective, reduce top managers' intention to take necessary risk and bear essential failure, and decrease top managers' professional pride and organizational commitment. However, all these three components of top managers' attitudes or behavior, i.e., long-term perspective, intention to take necessary risk, and professional pride, are critical determinants of firm performance for enterprises with higher technology intensity. Therefore, technology intensity can negatively affect the relationship between ECD and firm performance through the above three main mechanisms.

\section{Conclusions}

ECD is of strategic meanings to firm performance. However, the effect of ECD is not fixed and invariable, instead, it is contingent on some conditional variables. We argue that technology intensity is such a conditional variable. Reasonable ECD design should balance the functions of enhancing the healthy competition and keeping the sense of equity among top managers according to different technology intensity level. The paper investigates the moderating role of technology intensity in the relationship between ECD and firm performance.

Taking 3910 listed Chinese firms in manufacturing industry over 2008-2012 as the sample, choosing firm performance as the dependent variable, ECD as the explanatory variable, technology intensity as the moderating variable, and then the interaction analysis and sub-sample comparison analysis are carried on to test the moderating effect of technology intensity on the relationship between ECD and firm performance. Theoretical analysis and empirical analysis results both confirm that technology intensity can negatively moderate the relationship between ECD and firm performance. Such a contribution of this study indicates that a certain level of ECD in firms with higher technology intensity will bring more negative effect compared with that in firms with lower technology intensity. It can be further concluded that technology intensity would mitigate the negative side of ECD, while simultaneously enhance the positive side of ECD. In a word, other things being equal, the optimal level of ECD in firms with higher technology intensity will be much lower than that in firms with lower technology intensity. For firms with higher technology intensity, in order to maximize the value of ECD in improving firm performance, they should pay more attention to how to eliminate the dark effects of ECD on top managers. Especially they should consider, under the condition of higher ECD, how to deal with the possible decrease in top managers' intention of taking risk, the damage in top managers' long-term perspective, and the 
aversion in top managers' cooperation behavior in firms with higher technology intensity.

Though this study makes a good contribution to this field by finding the moderating effect of technology intensity, there are still several limitations. First, the representativeness of sample in this study is limited to the firms in manufacturing industry, which may weaken the validity of the conclusion. Therefore, future study should extend the range of sample by choosing more samples in all kinds of industries to test whether the results are robust across industries. Second, the research period in this study includes five years over 2008-2012, which may not reflect the dynamic change of the relationship among technology intensity, ECD and firm performance over time. Therefore, future research should focus more on longitudinal study with much longer time, for example, more than fifteen years. The last but not the least, because this paper chooses objective $\&$ secondary data as the measures instead of subjective \& perceived data, the essential mechanism of the relationship among technology intensity, ECD and firm performance can only be logically reasoned. It hard to confirm the validity of such reasoning, since top managers' long-term perspective, intentions to take risk and professional satisfaction can not be measured by secondary data in this paper. Therefore, in order to investigate the internal mechanism of the moderating effect of technology intensity on the relationship between ECD and firm performance, future research should adopt subjective \& perceived data by questionnaire and move the research in this field forward.

\section{Acknowledgements}

This research was financially supported by the Scientific Research Foundation of Ministry of Education of the PRC in Humanities and Social Sciences under Grant "14YJA630089" and 13YJAZH123", and the Shanxi Social Science Foundation under Grant "2014P04", the Project of National Social Science Foundation of China under the Grant "15BGL109" and the National Science Foundation under Grant "71402136" and "712721187".

\section{References}

[1]Adams, J. S. Towards an understanding of inequity. Journal of Abnormal and Social Psychology, 1963,67, pp.422-436.

[2]Andrew D. Henderson, and James W. Fredrickson. Top Management team coordination needs and the CEO pay gap: A competitive test of economic and behavior views. Academy of Management Journal, 2001, 44(1), pp.96-117.

[3]Anna Zalewska. Gentlemen do not talk about money: Remuneration dispersion and firm performance relationship on British boards. Journal of Empirical Finance, Volume 27, 2014, pp.40-57.

[4]Bambang Mahmudi, and Enok Nurhayati. The Influence of Board Governance Characteristics on Intellectual Capital Performance. Review of Integrative Business \&Economics Research, 2014, Vol.4(1), pp. 417-430. 
[5]Bing-Xuan Lin, and Rui Lu. Managerial power, compensation gap and firm performance Evidence from Chinese public listed companies. Global Finance Journal, Volume 20, 2009, Issue 2, pp.153-164.

[6]Brian G M Main, Charles A O'Reilly, and James Wade. Top Executive Pay: Tournament or Teamwork? Journal of Labor Economics, 1993, 11(4), pp.606-28

[7]Christine Congdon, Donna Flynn, Melanie Redman. Balancing "We" and "Me"Harvard Business Review, October 2014.

[8]Eriksson Tor. Executive Compensation and Tournament Theory: Empirical Tests on Danish Data. Journal of Labor Economics, 1999, 17, pp.262-280.

[9]Erin Landells, and Simon L. Albrecht. Organizational political climate: Shared perceptions about the building and use of power bases. Human Resource Management Review, Volume 23, Issue 4, December 2013, pp.357-365.

[10]Fang Hu, Xiaofei Pan, and Gary Tian. Does CEO pay dispersion matter in an emerging market? Evidence from China's listed firms. Pacific-Basin Finance Journal, Volume 24, 2013, pp. 235-255

[11]Hsiang-Lan Chen. Independent Directors' Human Capital and Firm Internalization. Asian Economic and Financial Review, 2014, 4(10), pp.1378-1388.

[12]Jayant R. Kale, Ebru Reis, Anand Venkateswaran. Pay inequalities and managerial turnover. Journal of Empirical Finance, Volume 27, June 2014, pp. 21-39.

[13]Jerayr Haleblian, and Sydney Finkelstein. Top Management Team Size, CEO Dominance, and firm performance: The Moderating Roles of Environmental Turbulence and Discretion. Academy of Management Journal, August 1, 1993 vol. 36 no.4, pp.844-863.

[14]Jing Chen, Mahmoud Ezzamel, and Ziming Cai. Managerial power theory, tournament theory, and executive pay in China. Journal of Corporate Finance, 2011, Volume 17, Issue 4, pp.1176-1199.

[15]John S. Earle, Csaba Kucsera, and Álmos Telegdy. Ownership Concentration and Corporate Performance on the Budapest Stock Exchange: Do Too Many Cooks Spoil the Goulash? Corporate Governance, 13(2), (2005), pp.254-264.

[16]J. W. Fredrickson, A. Davis-Blake, and W.M.G. Sanders. Sharing the wealth: Social comparisons and pay dispersion in the CEO's top team, Strategic Management Journal, 2010,31(10), pp.1031-1053.

[17]Kevin C.K. Lam, Paul B. McGuinness, and João Paulo Vieito. CEO gender, executive compensation and firm performance in Chinese-listed enterprises. Pacific-Basin Finance Journal, Volume 21, 2013, Issue 1, pp.1136-1159.

[18]K.W. Lee, B.Lev, and G.H.H. Yeo. Executive pay dispersion, corporate governance, and firm performance. Review of Quantitative of Finance and Accounting, 2008, 30(3), pp.315-338.

[19]Lazear E.P., and Rosen S. Rank-Order Tournaments as Optimum Labor Contracts. Journal of Political Economy, 1981, 89, 841-864. 
[20]Leete Laura. Wage Equity and Employee Motivation in Nonprofit and For-Profit Organization, Journal of Economic Behavior and Organization, 2000, 43, pp. 423-446.

[21]Martin J. Conyon, Simon I. Peck, and Graham Sadler. Corporate tournaments and executive compensation: Evidence from the U.K. Strategic Management Journal, 2001, 22(8), pp.805-815.

[22]Mason A. Carpenter, Wm.Gerard Sanders. The Effects of Top Management Team Pay and Firm Internationalization on MNC Performance. Journal of Management, Volume 30, Issue 4, August 2004, pp.509-528.

[23]M. Bloom, and J.G. Michel. The relationships among organizational context, pay dispersion, and managerial turnover. Academy of Management Journal, 2002, Vol.45, pp. 33-42.

[24]Melton, M., and Zone, T. S. Risk taking in tournaments. Managerial Finance, 2000, 26(7), pp.52-61.

[25]Nima Sepehr Sadeghian, Mohammad Mehdi Latifi, Saeed Soroush, and Zeinab Talebipour Aghabagher. Debt Policy and Corporate Performance: Empirical Evidence from Tehran Stock Exchange Companies. International Journal of Economics and Finance; Vol.4, 2012, No.11, pp.217-224.

[26] O'Reilly III, Charles A., Main Brian G., and Crystal Graef S. CEO Compensation as Tournament and Social Comparison: A Tale of Two Theories. Administrative Science Quarterly, 1988, Vol. 33 Issue 2, pp.257-274.

[27]P.A. Siegel, and D.C. Hambrick. Pay disparities within top management groups: evidence of harmful effects on performance of high-technology firms. Organization Science, 2005, Vol.16, No.3, pp259-274.

[28] Paul D. Sweeney, Dean B. McFarlin, and Edward J. Inderrieden. Using relative deprivation theory to explain satisfaction with income and pay level: A multistudy examination, Academy of management Journal, 1990, Vol. 33, No.2, pp.423-436.

[29]Pinar Mandaci, and Guluzar Gumus. Ownership Concentration, Managerial Ownership and Firm Performance: Evidence from Turkey. South East European Journal of Economics and Business, Volume 5, 2011, Issue 1, pp.57-66.

[30]Shuo Wang, and Chang-zheng Zhang. Effect of New CEO Power on Managerial Compensation Gap: A Conceptual Model. Proceedings of the International Conference on Industrial Engineering and Engineering Management, 2015, 07 Jan, pp.491-495.

[31]Vithessonthi Chaiporn, and Tongurai Jittima. The Effect of Firm Size on the Leverage-Performance Relationship during the Financial Crisis of 2007-2009. Journal of Multinational Financial Management, Vol.29, 2015, pp.1-29.

[32]Ying-Fen Lin, Yaying Mary Chou Yeh, Yu-Ting Shih. Tournament theory's perspective of executive pay gaps. Journal of Business Research, Volume 66, Issue 5, May 2013, pp.585-592. 